\title{
Dietary supplement use among patients with chronic kidney disease
}

\author{
Marzena Jakimowicz-Tylicka ${ }^{1}$, Michał Chmielewski ${ }^{1}$, Izabella Kuźmiuk-Glembin ${ }^{1}$, Piotr Sko- \\ nieczny', Grażyna Dijakiewicz', Grażyna Zdrojewska², Bolesław Rutkowski', Leszek Tylicki', \\ Alicja Dębska Ślizieńt
}

'Department of Nephrology, Transplantology and Internal Medicine, Medical University of Gdansk, Gdańsk, Poland; ${ }^{2}$ Family Medicine Centre, Medical University of Gdansk, Gdańsk, Poland

Background. Dietary supplements (DS) are available over the counter, but patients with impaired renal function are specifically at risk for toxicity when consuming certain DS. The aim of this study was to evaluate the prevalence and characteristics of DS use in patients with chronic kidney disease (CKD). Material and methods. A cross-sectional, controlled DS use survey (22 questions) was conducted among 180 CKD patients (stage 1-5, dialysis, kidney transplant), with 60 patients without CKD serving as controls. Results. DS use did not differ significantly between subjects with and without CKD, unless the CKD patients were on dialysis. In the CKD group, $20 \%$ admitted to use DS regularly and $22 \%$ did not take the mat all. In the controls, DS consumption was $17 \%$ and $13 \%$, respectively (NS). The DS use was higher among women ascompared to men (89\% vs. $70 \%$; $p<0.005)$, and people living in cities versus those living in the country side $(81 \%$ vs. $63 \% ; p<0.05)$. DS most commonly used were: vitamins, minerals, and herbs. Major indications for DS use included: musculoskeletal issues, general health improvement and prevention of urinary tract infections. Subgroup analyses revealed that dialysis patients were characterized by a significantly higher DS use in comparison to CKD stage 1-5 subjects and renal transplant recipients. The decision to introduce DS was made by the physician in $54 \%$ of cases; by a pharmacist in $9 \%$ of cases, and by the patients themselves in $37 \%$. Only $21 \%$ of patients with CKD, and $27 \%$ of subjects without CKD, declared knowledge of any possible sideeffects associated with DS (NS). Conclusions. The use of DS among patients with CKD is similar to patients without CKD, with the exception of those on dialysis. Vitamins and minerals were the most commonly reported DS consumed. The knowledge on potential side-effectof DS was limited to approximately one-fourth of those surveyed.

Key words: dietary supplements, vitamins, minerals, chronic kidney disease, dialysis, toxicity

Received: 21 February, 2018; revised: 10 April, 2018; accepted: 25 April, 2018; available on-line: 30 May, 2018

e-mail: chmiel@gumed.edu.pl

Abbreviations: DS, dietary supplements; CKD, chronic kidney disease; CKDND, non-dialysis dependent CKD; CKDD, dialysis subjects; CKDT, patients after kidney transplantation

\section{INTRODUCTION}

Dietary supplements (DS) are food products that contain concentrated vitamins, minerals, or other substances with a nutritional or physiological value. Initially, they were developed for individuals with micronutrient deficiencies that could not be corrected with a normal diet.

Consumption has grown among the general population, with the major indications for taking them being: maintaining good health and prevention of numerous diseases. Intense mass media marketing advertising DS as safe products with proven therapeutic potential, together with the widespread over-the-counter availability, have led to an enormous popularity of DS in the general population, as well as in various patient groups. The Food and Drug Administration estimates the number of DS products in the United States to exceed 55000 based on the National Institutes of Health 'Dietary Supplement Label Database' found online at https://www.dsld.nlm. nih.gov/dsld/index.jsp. Over 50\% of the American general population consumes at least one DS daily (Wallace et al., 2014).In Poland, the DS market has more than doubled in value over the years of 2005-2009 (Wierzejska et al., 2014).

Chronic kidney disease (CKD) is a state of renal insufficiency with impaired excretion of numerous metabolites and waste products. Decreased urinary clearance of DS and their metabolites could be potentially harmful in patients with CKD. Taking into account the prevalence of CKD, estimated in Poland to be at $6 \%$ of the general population (Zdrojewski et al., 2016), the issue of dietary supplementation in this patient group is of clinical importance.

The aims of the study presented here were to evaluate the prevalence of DS use in subjects with various forms and stages of CKD, to assess the major indications for DS consumption in CKD, and to obtain insight into the patients' knowledge and awareness concerning DS characteristics and potential side-effects.

\section{METHODS}

A cross-sectional controlled survey study was conducted in CKD patients in order to evaluate the selfmedication practice with DS. We primarily investigated the prevalence of DS use in CKD subjects, the types ofDS, as well as the major indications for their use.The classes of DS investigated were as follows: vitamins and minerals, omega-3 fatty acids, glucosamine, supplements for sexual potency, for weight loss, homeopathic agents, analgesics, herbs, and/or other. The study included 180 patients with CKD treated in the Department of Nephrology, Transplantology and Internal Medicine of the Medical University of Gdansk. CKD was diagnosed according to the KDOQI definition (National Kidney 
Table 1. Demographic dataof the study groups; CKD - chronic kidney disease, versus control group

\begin{tabular}{|c|c|c|c|}
\hline & All CKD patients & Control group & $p$-value \\
\hline Number of patients (n) & 180 & 60 & \\
\hline Male gender (\%) & $101(56.1 \%)$ & $32(53.3 \%)$ & NS \\
\hline Age (years) & $58.0 \pm 15.1$ & $57.3 \pm 14.3$ & NS \\
\hline \multirow[b]{2}{*}{$\begin{array}{l}\text { Living conditions: } \\
\text { Good Average Poor }\end{array}$} & & & NS \\
\hline & $\begin{array}{l}62(34.4 \%) \\
108(60.0 \%) \\
10(5.6 \%)\end{array}$ & $\begin{array}{lc}24 & (40.0 \%) \\
34 & (56.7 \%) \\
2 & (3.3 \%)\end{array}$ & \\
\hline \multirow[b]{2}{*}{$\begin{array}{l}\text { Education: } \\
\text { Basic/Professional Secondary } \\
\text { Higher }\end{array}$} & & & NS \\
\hline & $\begin{array}{l}22(12.2 \%) \\
106(58.9 \%) \\
52(28.9 \%)\end{array}$ & $\begin{array}{l}8(13.3 \%) \\
34(56.7 \%) \\
19(31.3 \%)\end{array}$ & \\
\hline \multirow[b]{2}{*}{$\begin{array}{l}\text { Place of residence: } \\
\text { Big city }>100000 \text { Small city }<100000 \text { Village }\end{array}$} & & & NS \\
\hline & $\begin{array}{l}123(68.3 \%) \\
36(20.0 \%) \\
21(11.7 \%)\end{array}$ & $\begin{array}{l}43(71.7 \%) \\
12(20.0 \%) \\
5(8.3 \%)\end{array}$ & \\
\hline $\begin{array}{l}\text { Co-morbidities: } \\
\text { Hypertension Diabetes mellitus } \\
\text { Cardiovascular disease }\end{array}$ & $\begin{array}{l}123(68.3 \%) \\
43(23.9 \%) \\
24(13.3 \%)\end{array}$ & $\begin{array}{l}32(53.3 \%)^{*} \\
5(8.3 \%)^{* *} \\
9(15.0 \%)\end{array}$ & $\begin{array}{l}<0.05 \\
<0.01 \\
\text { NS }\end{array}$ \\
\hline
\end{tabular}

NS = non-significant

2002). Patients were divided into subgroups: CKD stage 1-5 (CKDND, $\mathrm{n}=80)$, end-stage renal failure patients treated with hemodialysis or peritoneal dialysis (CKDD, $\mathrm{n}=50$ ), and subjects after kidney transplantation (CKDT, $\mathrm{n}=50)$. Glomerular filtration rate $(\mathrm{GFR})$ was estimated based on the CKD-EPI equation (Levey et al., 2009).

Sixty age-and gender-matched subjects without CKD serving as a control group were selected from the cohort of the Family Medicine Centre of the same hospital. The written anonymous survey consisted of 22 multiplechoice questions related to the respondents' demographic background, place of residence, level of education, living conditions, medical conditions and self-medication practices with DS. These included: the types of DS in

Table 2. Demographic data of the study subgroups:

CKDND - non-dialysis dependent CKD patients (CKD stage 1-5); CKDD - dialysis subjects; CKDT - patients after kidney transplantation

\begin{tabular}{|c|c|c|c|c|}
\hline & CKDND & CKDD & CKDT & $p$-value \\
\hline Number of patients $(n)$ & 80 & 50 & 50 & \\
\hline Age (years) & $64.2 \pm 14.7$ & $59.3 \pm 14.0$ & $50.1 \pm 12.5$ & $<0.001$ \\
\hline Gender M: n (\%) & $41(51 \%)$ & $28(56 \%)$ & $32(64 \%)$ & 0.37 \\
\hline $\begin{array}{l}\text { Other diseases: } \mathrm{n}(\%) \\
\text { Diabetes mellitus Hypertension CVD }\end{array}$ & $\begin{array}{l}29(36) \\
56(70) \\
14(17)\end{array}$ & $\begin{array}{l}7(14) \\
28(56) \\
7(14)\end{array}$ & $\begin{array}{l}7(14) \\
39(78) \\
3(6)\end{array}$ & $\begin{array}{l}0.001 \\
0.06 \\
0.17\end{array}$ \\
\hline $\begin{array}{l}\text { Education: } \mathrm{n}(\%) \\
\text { Basic Secondary Higher }\end{array}$ & $\begin{array}{l}7(9) \\
45(56) \\
28(35)\end{array}$ & $\begin{array}{l}7(14) \\
31(62) \\
12(24)\end{array}$ & $\begin{array}{l}8(16) \\
31(62) \\
11(22)\end{array}$ & $\begin{array}{l}0.62 \\
0.88 \\
0.47\end{array}$ \\
\hline $\begin{array}{l}\text { Place of residence: } \mathrm{n}(\%) \\
\text { City }>100000 \\
\text { City }<100000 \\
\text { Village }\end{array}$ & $\begin{array}{l}66(82) \\
7(9) \\
7(9)\end{array}$ & $\begin{array}{l}38(76) \\
10(20) \\
2(4)\end{array}$ & $\begin{array}{l}20(40) \\
20(40) \\
10(20)\end{array}$ & $\begin{array}{l}0.001 \\
0.001 \\
0.16\end{array}$ \\
\hline Living conditions: Good Average Poor & $\begin{array}{l}22(27) \\
55(69) \\
3(4)\end{array}$ & $\begin{array}{l}24(48) \\
20(40) \\
6(12)\end{array}$ & $\begin{array}{l}16(32) \\
33(66) \\
1(2)\end{array}$ & $\begin{array}{l}0.18 \\
0.008 \\
0.03\end{array}$ \\
\hline
\end{tabular}

use, frequency of DS use (never, sometimes, regularly i.e. $>1$ time/week), major indications, the source of DS (prescribed by the doctor, by the pharmacist, advised by massmedia, etc.), as well as the patient's awareness of the potential side-effects of the DS. Protocol of the study received approval from the Local BioethicsCommittee.

\section{Statistics}

Results were expressed as percentages (for categorical variables), mean and standard deviation or median and interquartile range. The assumption of normality was verified with the Kolmogorov-Smirnov test. The quantitative variables' differences were assessed by $t$-test, analysis of variance (ANOVA) or non-parametric Kruskal- 


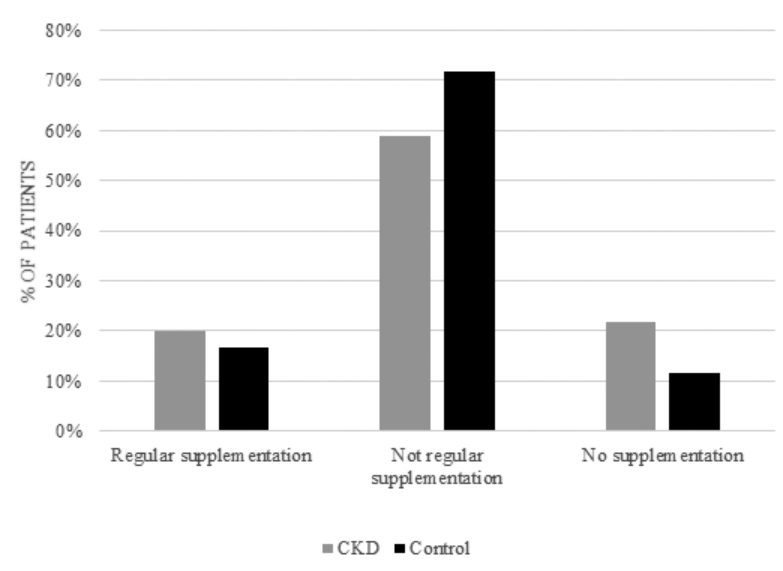

Figure 1. Regular, irregular, or no use of DS among CKD patients and controls.

Wallis test. Differences in prevalence between selected categories were measured using the Chi $(\chi 2)$ square test. A $p$-value $<0.05$ was considered to be statistically significant. Statistical processing of the results was performed with the use of the statistical software STATISTICA PL v 12.0 (Statsoft, Kraków, Poland).

\section{RESULTS}

The demographics of the studied groups are depicted in Table 1. Patients with CKD declared greater comorbidity, as compared to subjects from the control group. Subgroup analyses of CKD patients revealed that renal transplant recipients (CKDT) were younger and lived in less populated places than CKDND and CKDD patients (Table 2). There were also less diabetic subjects among the transplanted and dialysis patients, as compared to CKDND group.

The practice of DS use was found not to be significantly different between subjects with and without CKD (Fig. 1). Among patients with CKD, gender, age and place of residence were significantly associated with DS use. Women had higher DS use than men $(89 \%$ vs. $70 \%$; $p=0.003$ ), and DS was higher in older persons (mean age of patients regularly taking DS vs. those taking the mir regularly or never was $63.4 \pm 13.5$ vs. $57.8 \pm 15.3$, respectively; $p=0.045$ ) and in people living in cities in compari-

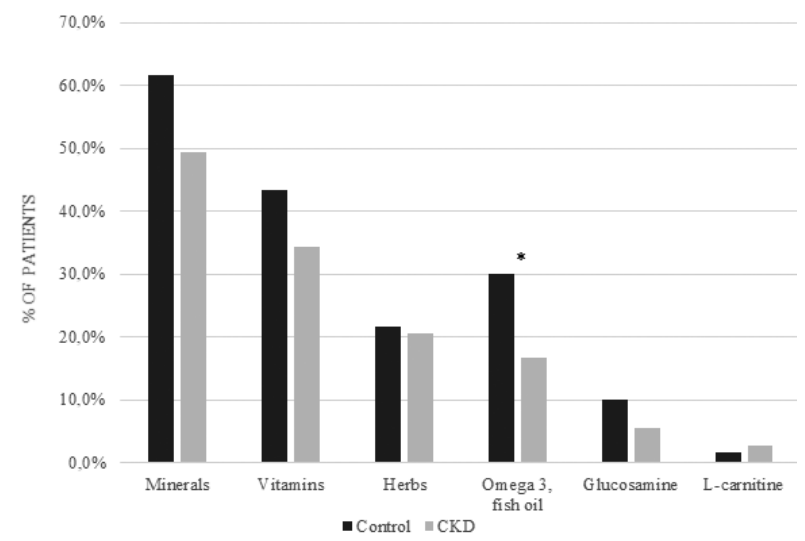

Figure 2. The most common DS consumed by CKD patients and controls.

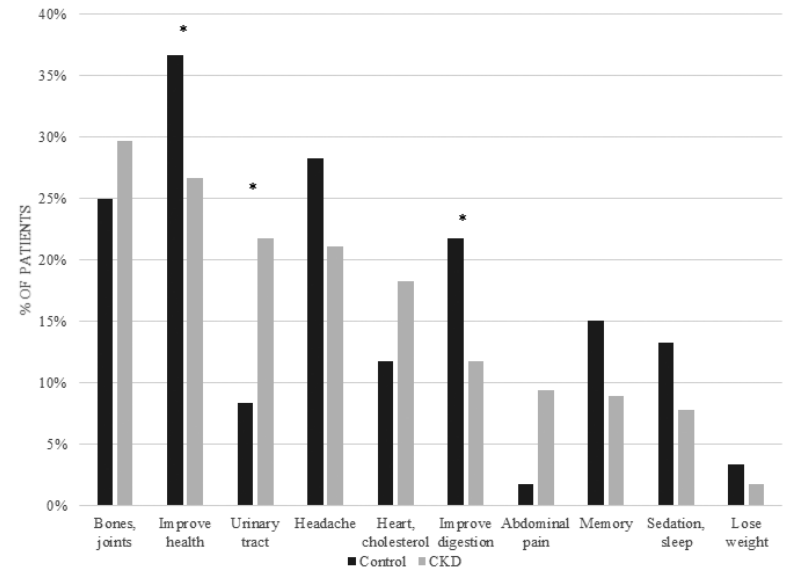

Figure 3. Common conditions/diseases reported for DS use among CKD patients and controls.

son to patients living in the countryside $(81 \%$ vs. $63 \%$; $p=0.049$ ).

In the CKD group, DS most commonly used were: minerals ubstances, vitamins, and herbs (Fig. 2). Major indications related to DS consumption reported by CKD patients were: musculoskeletal issues, general health improvement and prevention of urinary tract infections (Fig. 3). The decision to introduce DS was made by the patient's doctor in $54 \%$ of cases; by a pharmacist in $9 \%$ of cases, and by the patients themselves in 37\% of cases. The results obtained in the control group did not differ significantly in this regard $(50 \%, 13 \%$ and $37 \%$,respectively).

The vast majority $(84 \%)$ of patients with CKD declared that their doctor was informed about the DS used. In the control group, this percentage was lower $(62 \% ; p=0.001)$.

Only $21 \%$ of patients with CKD, and $27 \%$ of subjects without CKD declared knowledge of any possible side-effects associated with DS use (NS). Other patients stated that DS were completelysafe.

Subgroup analyses revealed that CKDD patients were characterized by a significantly higher DS use in comparison to CKDND and CKDT renal transplant recipients (Fig. 4). CKDD reported taking more vitamin sandl-carnitine than other CKD patients, while the use of omega-3 fatty acids was the most frequent in the CKDND group (Table 3). Although there were differences

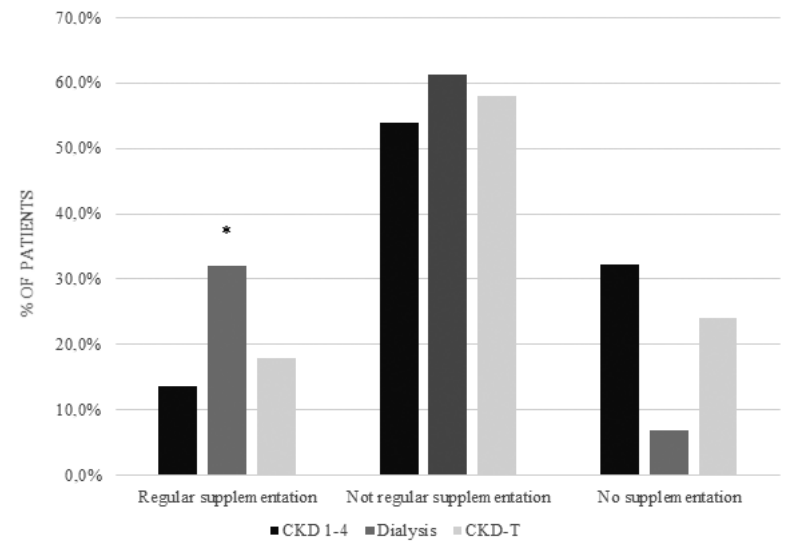

Figure 4. DS use in CKD subgroups. 
Table 3. The most common DS consumed by CKD subgroups;

CKDND - non-dialysis dependent CKD patients (CKD stage 1-5); and CKDD - dialysis subjects; CKDT - patients after kidney transplantation

\begin{tabular}{llccc}
\hline & CKDND & CKDD & CKDT & $p$-value \\
\hline Minerals & $47.5 \%$ & $56 \%$ & $46 \%$ & 0.544 \\
\hline Vitamins & $23.7 \%$ & $46 \%$ & $40 \%$ & 0.021 \\
\hline Herbs & $22.5 \%$ & $22 \%$ & $16 \%$ & 0.642 \\
\hline Omega-3, fish oil & $25 \%$ & $6 \%$ & $6 \%$ & 0.015 \\
\hline Glucosamine & $7.5 \%$ & $2 \%$ & $0 \%$ & 0.407 \\
\hline L-Carnitine & $1.25 \%$ & $8 \%$ & 0.027 \\
\hline
\end{tabular}

in the indication for DS use among the CKD subgroups, they reached a statistical significance only in the case of DS used for headache, as this indication was more prevalent in CKDD and CKDT patients, as compared to CKDND subjects (Table 4).

\section{DISCUSSION}

The study presented here reveals that DS use is as prevalent in CKD patients as it is in the general population. This finding is of clinical significance because despite the wide spread consumption of DS, there is a lack of data on DS use among patients with CKD. In the few studies from various parts of the world completed up to date, the prevalence of DS use among CKD patients was similar to that found in the present evaluation (Kara, 2009; Nowack et al., 2009, Tangkiatkumjai et al., 2014). Analysis within the CKD population revealed that there are some differences among particular groups. The higher prevalence of vitamin use in dialysis patients might be explained by the more frequent use of vitamin $\mathrm{D}$ in this patient group, as compared to CKDND and renal transplant subjects. However, it has to be highlighted that the study presented here evaluated only the use of over-the-counter medications. In Poland, cholecalciferol belongs to this group, while most CKD patients take 1-hydroxy-cholecalciferol, which is sold on prescription only, and therefore has not been included in this analysis. The higher proportion of patients taking fish oil supplements in the CKDND cohort might derive from the belief of nephroprotective properties of this DS.

Intense advertising and over-the-counter availability results in consumption of DS that is growing worldwide, with vitamins and minerals commonly used to promote general health and decrease the risk of chronic diseases. This holds true despite the fact that the efficacy of DS is highly doubtful. There is no doubt that in specific cases of mineral and/or vitamin deficiencies, DS are indispensable. However, large, well-designed studies in the general population, as well as in various patient groups, consistently show no effect of DS use on mortality, cardiovascular disease, or cognitive function. High-dose oral multivitamin and multimineral regimen used as a secondary cardiovascular prevention in patients with a history of myocardial infarction did not reduce cardiovascular events in a statistically significant way (Lamas et al., 2013). In a long-term, randomized, placebo-controlled trial among almost six thousand men aged 65 years or older, those assigned a daily multivitamin supplement had similar overall cognitive performanceas those receiving a placebo (Grodstein et al., 2013). When evaluating the studies combined in the form of meta-analysis, there was no evidence of supplements affecting cardiovascular disease, cancer, or all-cause mortality in healthy individuals without known nutritional deficiencies(Fortmann et al., 2013).

In CKD patients, DS are used for similar reasons as in the general population. The major indications include

Table 4. Indications for DS use in the CKD subgroups;

CKDND - non-dialysis dependent CKD patients (CKD stage 1-5); CKDD - dialysis subjects; and CKDT - patients after kidney transplantation

\begin{tabular}{lcccc}
\hline & CKDND & CKDD & CKDT & p-value \\
\hline Musculoskeletal & $35 \%$ & $30 \%$ & $20 \%$ & 0.19 \\
\hline General health improvement & $20 \%$ & $38 \%$ & $26 \%$ & 0.77 \\
\hline Urinary tract & $26 \%$ & $12 \%$ & $24 \%$ & 0.14 \\
\hline Headaches & $12 \%$ & $30 \%$ & $26 \%$ & 0.04 \\
\hline Cardiovascular system & $21 \%$ & $18 \%$ & 0.58 \\
\hline Digestion & $10 \%$ & $12 \%$ & 0.78 \\
\hline Abdominal pain relief & $9 \%$ & $10 \%$ & $10 \%$ & 0.96 \\
\hline Memory improvement/preservation & $9 \%$ & $10 \%$ & $8 \%$ & 0.94 \\
\hline Sedation/sleep facilitation & $6 \%$ & $6 \%$ & $12 \%$ & 0.42 \\
\hline Weight reduction & $4 \%$ & $1 \%$ & $0 \%$ & 0.27 \\
\hline
\end{tabular}


general health improvement and protection of bones and joints. As renalosteodystrophy is a common complication of CKD, this finding does not surprise. Our study reveals that the use of DS affecting the urinary tract is more prevalent in CKD subjects, in comparison to controls with no kidney disease. The major supplements reported by patients in this regard were various herbs for prevention of urinary tract infections, and for improvement of urination. For dialysis patients, dietary recommendations include supplementation of vitamins that are lost to dialysate during the treatment (Clase et al., 2013). Calcium supplements are advised for prevention of renal osteodystrophy. Data from the literature also demonstrates more specific indications for DS in this patient population, as for instance fish oil supplementation and aspirin for arteriovenous fistula protection in patients requiring hemodialysis (Irish et al., 2017) or alpha-tocopherol for prevention of cardio-vascular mortality in the highly burdened diabetic hemodialysis cohort (Espe et al., 2013). Similarly to the results in the general population, these DS have not been found to be associated with clinical benefit in most studies (Espe et al., 2013; Irish et al., 2017), although there are reports on improvement in lipid profile, oxidative stress, pruritus or erythropoietin demand in CKD patients following intake of omega-3 polyunsaturated fatty acids (Vergili-Nelsen, 2003; Bouzidi et al., 2010).

However, patients with CKD constitute a different population than people with no kidney disease. Impaired renal function can lead to accumulation of DS and/or their metabolites for which the urinary tract is the primary path of elimination. That is the case of magnesium. Mild hyper magnesaemia develops in most CKD patients when the glomerular filtration rate is less than 30 $\mathrm{ml} /$ minute, since magnesium excretion decreases even though fractional excretion of magnesium is increased (Felsenfeld et al., 2015). Nevertheless, magnesium supplementation is highly prevalent in CKD subjects. It has to be acknowledged though, that increased magnesium concentration might be beneficial for CKD subjects, as it has been shown to inhibit phosphate-induced vascular calcification in experimental settings (Bressendorff et al., 2017). Currently ongoing studies will probably reveal whether this favorable property is of clinical significance (Bressendorff et al., 2017). Nevertheless, most of multimineral DS contain phosphates and numerous multivitamin DS contain potassium. The dangers associated with increased consumption of both in the CKD population are well acknowledged and obvious.

However, some of DS can, independently from renal function, be harmful to kidneys. Aristolochic acid, found in some herbal supplements, is an acknowledged cause of 'Chinese herbs' nephropathy and is involved in the pathomechanism of Balkan endemic nephropathy (Jadot et al., 2017). Experimental data, as well as some clinical reports, point to the possibility of kidney injury caused by glucosamine through induction of apoptosis in the tubular and mesangial cells of the kidney (Gueye et al., 2016). High vitamin $E$ consumption leads to increased content of biomarkers of tissue toxicity and oxidative stress in the kidneys of mice (Jansen et al., 2016). In general, DS containing aristolochic acid, glucosamine, potassium, and phosphates ought to be avoided in CKD patients. In renal transplant subjects, all DS that interfere with the cytochrome P450 pathways should not be used because of the risk of interactions with immunosuppressive medicines (Chen et al., 2012). Comprehensive lists of potentially nephrotoxic DS are available online and in the literature (Brown, 2017).
The knowledge on the potential side-effects of dietary supplementation is scarce, both in the general population, as well as in CKD patients. Only $1 / 5$ of the studied cohort of CKD subjects declared any awareness of any possible risks associated with DS use. The remaining $80 \%$ of patients stated that DS were completely safe. This finding underlines the importance of a meticulously elicited medical history of DS use, and enlightening the patients of the potential risks associated with dietary supplementation.

The major limitations of the study presented here include its cross-sectional character, and a relatively small sample size. The DS were classified arbitrarily, and some agents from one class of DS could be used for various reasons, as for instance vitamin $\mathrm{C}$ for urinary tract infection prevention. However, while formulating the questionnaire, the aim was to make it as easy and straightforward for the patient as possible. Nevertheless, it included 22 questions.

In conclusion, the prevalence of DS use is similarly high in the CKD patients as it is in people with preserved renal function, with the exception of those on dialysis. In addition, the pattern of DS use varies slightly with CKD subjects interested in improving urinary tract function. The patients' knowledge on the side-effects of DS is very limited. Taking into account the potential risks associated with the accumulation of DS in the course of CKD and/or the nephrotoxic potential of some DS, the necessity of a meticulous interview on DS use, and of comprehensive information provided to the patient, seems of crucial importance.

\section{Acknowledgements of Financial Support}

This studydid not receive any specific grant from funding agencies in the public, commercial, or not-forprofit sectors.

\section{REFERENCES}

Bouzidi N, Mekki K, Boukaddoum A, Dida N, Kaddous A, Bouchenak M (2010) Effects of omega-3 polyunsaturated fatty-acid supplementation on redox status in chronic renal failure patients with dyslipidemia. J Ren Nutr 20: 321-328. doi: 10.1053/j.jrn.2010.01.002

Bressendorff I, Hansen D, Schou M, Kragelund C, Brandi L (2017) The effect of magnesium supplementation on vascular calcification in chronic kidney disease-a randomised clinical trial (MAGiCALCKD): essential study design and rationale. BMJ Open 7: e016795. doi: 10.1136/bmjopen-2017-016795

Brown AC (2017) Kidney toxicity related to herbs and dietary supplements: Online table of case reports. Part 3 of 5 series. Food Chem Toxicol 107: 502-519. doi: 10.1016/j.fct.2016.07.024

Chen XW, Sneed KB, Pan SY, Cao C, Kanwar JR, Chew H, Zhou SF (2012) Herb-drug interactions and mechanistic and clinical considerations. Curr Drug Metab 13: 640-651

Clase CM, Ki V, Holden RM (2013) Water-soluble vitamins in people with low glomerular filtration rate or on dialysis: a review. Semin Dial 26: 546-567. doi: 10.1111/sdi.12099

Espe KM, Raila J, Henze A, Blouin K, Schneider A, Schmiedeke D, Krane V, Pilz S, Schweigert FJ, Hocher B, Wanner C, Drechsler C, German D, I. Dialysis Study (2013) Low plasma alpha-tocopherol concentrations and adverse clinical outcomes in diabetic hemodialysis patients. Clin J Am Soc Nephrol 8: 452-458. doi: 10.2215/ CJN.04880511

Felsenfeld AJ, Levine BS, Rodriguez M (2015) Pathophysiology of calcium phosphorus and magnesium dysregulation in chronic kidney disease. Semin Dial 28: 564-577. doi: 10.1111/sdi.12411

Fortmann SP, Burda BU, Senger CA, Lin JS, Whitlock EP (2013) Vitamin and mineral supplements in the primary prevention of cardiovascular disease and cancer: An updated systematic evidence review for the U.S. Preventive Services Task Force. Ann Intern Med 159: 824-834. doi: 10.7326/0003-4819-159-12-201312170-00729

Grodstein F, O’Brien J, Kang JH, Dushkes R, Cook NR, Okereke O, Manson JE, Glynn RJ, Buring JE, Gaziano M, Sesso HD (2013) Long-term multivitamin supplementation and cognitive function 
in men: a randomized trial. Ann Intern Med 159: 806-814. doi: 10.7326/0003-4819-159-12-201312170-00006

Gueye S, Saint-Cricq M, Coulibaly M, Goumri N, Guilbeau-Frugier C, Quentin H, Ged E, Sidi Aly A, Rostaing L (2016) Chronic tubulointerstitial nephropathy induced by glucosamine: a case report and literature review. Clin Nephrol 86: 106-110

Irish AB, Viecelli AK, Hawley CM, Hooi LS, Pascoe EM, Paul-Brent PA, Badve SV, Mori TA, Cass A, Kerr PG, Voss D, Ong LM, Polkinghorne KR, A. Omega-3 Fatty and G. Aspirin in Vascular Access Outcomes in Renal Disease Study Collaborative (2017) Effect of fish oil supplementation and aspirin use on arteriovenous fistula failure in patients requiring hemodialysis: a randomized clinical trial. JAMA Intern Med 177: 184-193. doi: 10.1001/jamainternmed.2016.8029

Jadot I, Decleves AE, Nortier J, Caron N (2017) An integrated view of aristolochic acid nephropathy: update of the literature. Int J Mol Sci 18. doi: $10.3390 /$ ijms18020297

Jansen E, D. Viezeliene P. Beekhof E. Gremmer and L. Ivanov (2016) Tissue-specific effects of vitamin E supplementation. Int J Mol Sci 17. doi: $10.3390 /$ ijms 17071166

Kara B (2009) Herbal product use in a sample of Turkish patients undergoing haemodialysis. J Clin Nurs 18: 2197- 2205. doi: 10.1111/j.1365-2702.2008.02730.x

Lamas GA, Boineau R, Goertz C, Mark DB, Rosenberg Y, Stylianou M, Rozema T, Nahin RL, Lindblad L, Lewis EF, Drisko J, Lee KL, T. Investigators (2013) Oral high-dose multivitamins and minerals after myocardial infarction: a randomized trial. Ann Intern Med 159: 797-805. doi: 10.7326/0003-4819-159-12-201312170-00004s

Levey AS, Stevens LA, Schmid CH, Zhang YL, Castro AF, Feldman 3rd HI, Kusek JW, Eggers P, Van Lente F, Greene T, Coresh J,
Ckd EPI (2009) A new equation to estimate glomerular filtration rate. Ann Intern Med 150: 604-612

National Kidney F (2002) K/DOQI clinical practice guidelines for chronic kidney disease: evaluation classification and stratification. Am J Kidney Dis 39 (2 Suppl 1): S1-266

Nowack R, Balle C, Birnkammer F, Koch W, Sessler R, Birck R (2009) Complementary and alternative medications consumed by renal patients in southern Germany. J Ren Nutr 19: 211-219. doi: 10.1053/j. jrn.2008.08.008

Tangkiatkumjai M, Boardman H, Praditpornsilpa K, Walker DM (2014) Reasons why Thai patients with chronic kidney disease use or do not use herbal and dietary supplements. BMC Complement Altern Med 14: 473. doi: 10.1186/1472-6882-14-473

Vergili-Nelsen JM (2003) Benefits of fish oil supplementation for hemodialysis patients. J Am Diet Assoc 103: 1174-1177. doi: 10.1053/ jada.2003.50577

Wallace TC, McBurney M, Fulgoni 3rd VL (2014) Multivitamin/ mineral supplement contribution to micronutrient intakes in the United States 2007-2010. I Am Coll Nutr 33: 94-102. doi: 10.1080/07315724.2013.846806

Wierzejska R, Jarosz M, Siuba M, Rambuszek M (2014) Assessing patients' attitudes towards dietary supplements. Rocz. Panstw Zakl Hig 65: 317-323 (in Polish)

Zdrojewski L, Zdrojewski T, Rutkowski M, Bandosz P, Krol E, Wyrzykowski B, Rutkowski B (2016) Prevalence of chronic kidney disease in a representative sample of the Polish population: results of the NATPOL 2011 survey. Nephrol Dial Transplant 31: 433-439. doi: 10.1093/ndt/gfv369 